Ayliffe, G. A. J. (1964). Nature (Lond.), 201, 1032.

Barber, M. (1964). F. gen. Microbiol. In press.

Chabbert, Y. (1957). Ann. Inst. Pasteur, 93, 289.

Cowan, S. T., and Steel, K. J. (1961). F. Hyg. (Lond.), 59, 357.

Dolan, M. M., Bondi, A., Hoover, J. R. E., Tumilowicz, R., Stewart, R. C., and Ferlauto, R. J. (1961). Antimicrob. Agents Chemother.

p. 648 .

Rhodes, R. E., Steelman, R. L., Stewart, R. C., and Ferlauto, R. J. (1961). Ibid., p. 655 .

Farquhar, J. D., Dolan, M. M., Dorman, M. G., Ziv, D. S., and Ferlauto, R. J. (1961). Ibid., p. 661 . Fleming, P. C., Goldner, M., and Glass, D. G. (1963). Lancet, 1,

Garrod, L. P., and Waterworth, P. M. (1962). F. clin. Path., 15, 328.

Knox, R., and Smith, J. T. (1961). Lancet, 2, 520.
Klein, J. O., and Finland, M. (1963). New Engl. F. Med., 269, 1019, 1074 , 1129 .

Sabath, L. D., Steinhauer, B. W., and Finland, M. (1963a). Amer. 7. med. Sci., 246,385 .

- (1963b). New Engl. 7. Med., 269, 1215.

Perret, C. J. (1954). Nature (Lond.), 174, 1012.

Richards, H. C., Housley, J. R., and Spooner, D. F. (1963). Ibid., 199, 354.

Rolinson, G. N. (1961). Brit. med. 7., 1, 125.

Rosenman, S. B., and Warren, G.' H. (1961). Antimicrob. Agents Chemother., p. 611 .

Walters, E. W., Romansky, M. J., and Johnson, A. C. (1962). Ibid., p. 706.

Yurchenco, J. A., Hopper, M. W., and Warren, G. H. (1961). Ibid., p. 620 .

\title{
Changing Age of the Menopause
}

\author{
D. J. FROMMER,* M.B., B.S., B.SC.
}

Brit. med. F., 1964, 2, 349-351

It is a common observation that adolescence nowadays occurs at a much earlier age than in the last century. Many surveys in different countries on body height and weight, bone length, and sexual development support this belief (Tanner, 1962). The average age of menarche has fallen in Great Britain from 15.5 years in 1855 (Rigden, 1870) to about 13.1 years in 1957 (Wilson and Sutherland, 1960). The average age of menarche raises the question of whether there has been a change in the average age of menopause over this period, and whether the total period of menstruation in women has increased or decreased since the last century.

There has been little research into these questions, and the present investigation was designed to throw some light on this problem.

\section{Methods}

Previous investigations into the age of the menopause have indicated that many women cannot accurately remember their age when their menopause occurred, even a few years after the event. Thus in the report of the Medical Women's Federation (1933) the number of women giving their age of menopause at 40,45 , or 50 years were very much higher than those in the years immediately preceding or succeeding these three ages. This was obviousiy due to women " rounding off" their age of menopause to the nearest multiple of five.

The method of probit analysis (Finney, 1952) was therefore adopted to overcome this source of error. This method allows the proportion of women at any particular age who have reached their menopause to be calculated without knowing the age of menopause of any one of the women. Only two pieces of information are required about any woman: (a) whether she had reached her menopause, and $(b)$ her age when giving the information concerning her menstrual state. If a sufficient number of women are used in the investigation, the percentage of women at any age who have reached the menopause can be calculated with a high degree of accuracy.

Since questioning a sufficient number of women was impracticable, the information on the menstrual history of the women in this investigation was obtained from the records of the Royal Free Hospital 1951-61. Patients were chosen according to the following criteria. (a) They appeared to be well. In cases of cholelithiasis admitted with acute cholecystitis,

* Formerly House-physician, Royal Free Hospital, London. Now Housesurgeon, Barnet General Hospital, Barnet, Herts. the patients had to have a previous history of good health. No cases of carcinomatosis from carcinoma of the breast nor any cases treated with hormones or irradiation were included in this investigation. (b) No cases with systemic or endocrine diseases-for example, diabetes mellitus-were included. (c) Patients' diseases were those which it was believed neither influenced menstrual bleeding nor the menopause, and vice versa. This was done in the hope of avoiding biasing the results.

Of the 699 cases examined, 443 were included in the present series. The rest were rejected because of lack of information in the records or because the patients did not meet the above criteria.

Women aged between 40 and 55 years were divided into 16 age-groups. Since records usually gave the age to the previous birthday only, the average age of the group was corrected by an extra half-year, since it was assumed that both the birthdays and the dates of recording menstrual state were randomly and evenly distributed throughout the year. For example, the 48-year group had a mean of 48.5 years.

The percentage of women in each age-group who had reached their menopause was found. The criterion of whether a woman was menopausal was a history of a ininimum of nine months' absence of bleeding before the observation of the menstrual state. This criterion meant that a value of percentage of women menopausal in any age-group in reality refers to a group with a mean age 9 months younger than the nominal age of the group-for example, 47.75 years instead of 48.5 years. A graph was drawn by plotting percentage of menopausal women in each age-group against the average age of each group. An S-shaped regression line for all the points on the graph and another line for the points between 45.75 and 54.75 years were calculated by means of probit transformation (Finney, 1952), and from each line a value was obtained for the age at which $50 \%$ of women reached their menopause.

\section{Results}

Of the 443 women 52 were single and 391 were married or single with children. The average number of childreiz per woman was 2.02. The various complaints for which these women attended hospital are given in Table $I$. The numbers of menopausal women at the various ages are shown in Table II.

The $50 \%$ point on the regression line (integrated frequency distribution curve) for $45.75-54.75$ years is 50.10 years (Fig. 1) 
TABLE I

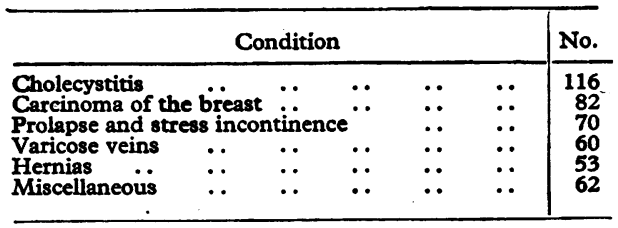

and is very close to the corresponding point 49.82 years on the regression line for $39.75-54.75$ years. The low value for the $\chi^{2}$ test for the regression line 45.75-54.75 years shows that the line fits the points over this range well so that it is consistent with a derivation from a normal distribution curve. The higher value for the $\chi^{2}$ test for the regression line for the whole series may be due to: (a) this method being less accurate when values at the extremes-that is, below $16 \%$ and above found in North America that the mean age of menopause of 30 women with cholecystitis was 47.7 years, compared with an average of 47.1 years for his total series of 567 cases. In his series patients with prolapse had a much reduced mean age of menopause-45.6 years. Hauser et al. (1961) found that two large series of patients with prolapse in Basle in 1900 and in 1950 had a slightly increased mean age of menopause (0.2 year in 1900 and 0.1 year in 1950). However, the same authors showed that in both a series of prolapse from Israel and in another one from Finland the mean age of menopause was slightly lower ( 0.5 year in Israel and 0.3 year in Finland) than in a total series of mixed patients in each country. Thus prolapse may be associated with a slightly lower age of menopause-less than 0.5 year.

The report of the Medical Women's Federation (1933) gave a mode of 50 years and a median value of about 47.5 years for

\begin{tabular}{|c|c|c|c|c|c|c|c|c|c|c|c|c|c|c|c|c|}
\hline $\begin{array}{l}\text { Mean Age* of } \\
\text { of Group: }\end{array}$ & $39 \cdot 75$ & $40 \cdot 75$ & 41.75 & $42 \cdot 75$ & 43.75 & $44 \cdot 75$ & $45 \cdot 75$ & $46 \cdot 75$ & $47 \cdot 75$ & $48 \cdot 75$ & $49 \cdot 75$ & $50 \cdot 75$ & $51 \cdot 75$ & $52 \cdot 75$ & 53.75 & $54 \cdot 75$ \\
\hline $\begin{array}{l}\text { No. in group ... } \\
\text { "menopausal }\end{array}$ & 26 & 27 & $\begin{array}{r}24 \\
2\end{array}$ & 25 & $\begin{array}{r}28 \\
1\end{array}$ & $\begin{array}{r}29 \\
5\end{array}$ & $\begin{array}{r}30 \\
8\end{array}$ & $\begin{array}{r}29 \\
6\end{array}$ & $\begin{array}{r}31 \\
8\end{array}$ & $\begin{array}{l}32 \\
10\end{array}$ & $\begin{array}{l}28 \\
13\end{array}$ & $\begin{array}{l}28 \\
15\end{array}$ & $\begin{array}{l}28 \\
22\end{array}$ & $\begin{array}{l}26 \\
19\end{array}$ & $\begin{array}{l}30 \\
24\end{array}$ & $\begin{array}{l}22 \\
19\end{array}$ \\
\hline$\%$ menopausal & 3.9 & $\mathbf{0}$ & $8 \cdot 5$ & $4 \cdot 0$ & 3.6 & $17 \cdot 3$ & $26 \cdot 7$ & $20 \cdot 7$ & $25 \cdot 8$ & $31 \cdot 1$ & $46 \cdot 3$ & 53.5 & $78 \cdot 4$ & $73 \cdot 0$ & $80 \cdot 0$ & $86 \cdot 2$ \\
\hline
\end{tabular}

- Corrected for 9. months' criterion of menopause.

Age-group $=39-54 \cdot 75$ years : $50 \%$ menopausal at $49.82+0.68$ years $(50.50-49 \cdot 15$ years $) . \quad P=0.95$. $x^{2}(14)=12 \cdot 1=0.70>P>0.50$.

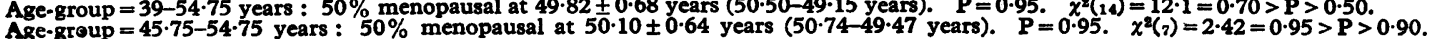

$84 \%$ - of the integrated frequency distribution curve are included (Finney, 1962), and (b) a slight negative skew to the distribution curve from which the integrated frequency distribution curve is derived. The data of Way (1954), Awon (1957), and Benjamin (19.60) show such a skew, whereas those of Sanes (1918) and Norris (1919) do not.

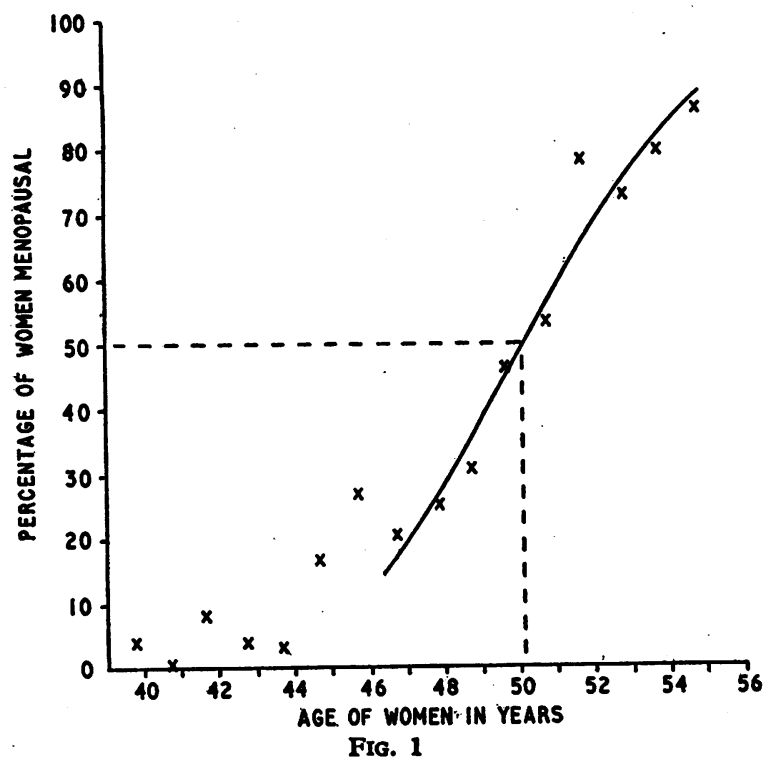

The median (50\%) value of 50.1 years is therefore the more accurate value of the two, and, since the regression line from 45.75 to 54.75 years is derived from a normal distribution curve, the mode (or peak age of menopause) is also 50.1 years. The mean age of menopause of the whole series is less, and cannot be determined by this method because of the probable negative skew of the distribution curve.

\section{Discussion}

The results of this investigation can be applied to the general population only if the conditions from which the women in this series suffered did not influence their age of menopause, or if bias due to the diseases cancelled each other out. Sanes (1918) the age of menopause. Both averages are of little value-the mode because of the marked " rounding off" effect mentioned above, and the median because the series did not give figures for the number of women having their menopause over the age of 52 years. Way (1954) in 1938 found a modal age of menopause of 50 years in 536 English women but found that only $31 \%$ of them had their menopause after 50 years of age. In a series of 107 normal women Awon (1957) found a modal age of menopause of 48 years, and only $27 \%$ of the women continued to menstruate after 50 years. Benjamin (1960), in a survey of 1,000 white South African women, noted a very sharp peak $(17.9 \%)$ at 50 years for the age of menopause. This is probably due in part to the "rounding off" phenomenon. Making a 0.5 -year correction for each age-group in his series (see Methods), a median age of menopause of about 50.3 years can be calculated from his data.

The smaller proportion of women having their menopause after 50.0 years in the surveys of Way and Awon as compared with that of Benjamin and of the present survey may be due to differences in health, marital status, pregnancies, etc., of the women in the different investigations. It is interesting that the distribution of age of menopause in the series of Way and Awon shows a stronger negative skew than that in Benjamin's or in the present series.

The findings of the present median age of menopause of women in Great Britain of about 50 years represents an increase of about 4 years since the middle of the last century. Guy (1845), in a survey of 400 women, obtained values of 45.0 years for the modal age of menopause. The value of the median age of menopause calculated from the data of Tilt's (1853) investigation of 284 women is about 46.6 years.

This phenomenon is not peculiar to Great Britain. Backman's (1948) studies have shown that the delay in the age of menopause has occurred in most European countries since the last century (Fig. 2). From his analysis of early literature Backman believed that the mean age of menopause was about 40 years in ancient times and about 45 years between 1500 and 1800.

The reason for this delay in the age of menopause is not known. It seems unlikely to be due to families being smaller now than in the last century, since few pregnancies are associated with early menopause (Sanes, 1918 ; Benjamin, 1960). Better nutrition and improved environmental conditions have been given credit for earlier adolescence, including menarche, 
since both factors are known to be associated with increased and earlier development. The same factors may therefore be responsible for the accompanying delay in the menopause. Tanner (1962) suggests that the pituitary gland may be involved in both the change in age of menarche and of menopause, and this is made more plausible by the fact that adolescence is not only reached earlier than previously but that boys and girls are also bigger than before.

Since an earlier age of menarche accompanies an earlier and increased development at adolescence it seems possible that a later age of menopause may accompany a delayed or decreased rate of " physiological degeneration"-that is, decreased rate of ageing. The answer to this problem, however, requires further research.

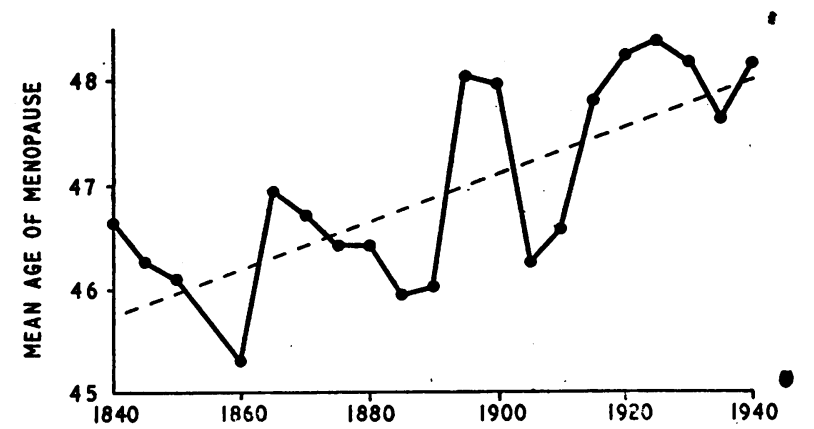

Fig. 2.-Mean age of menopause 1840-1940, compiled from 63 series from European countries. Reproduced from Acta Anatomica, 1948, 4, 456, with the permission of the author, G. Backman, and the publishers, S. Karger, Basle and New York.

\section{Summary}

The modal age and median age of menopause of 443 women from 1951 to 1961 were found to be 50.1 years, using the probit transformation. This represents an increase of about 4 years in the age of menopause compared with that of a hundred years ago. The causes of this delay in the menopause are discussed.

I am grateful to Professor R. E. M. Bowden and Mr. P. R. Norris for their help and encouragement; to Mrs. M. Kerr, of the M.R.C., for statistical advice; to Dr. David Ingram for help in collecting some of the data; and to the Records Department of the Royal Free Hospital.

\section{REFERENCES}

Awon, M. P. (1957). F. Obstet. Gynaec. Brit. Emp., 64, 50.

Backman, G. (1948). Acta Anat. (Basel), 4, 421.

Finney, D. J. (1952). Probit Analysis, 2nd ed. Cambridge Univ. Press, London.

Guy, W. (1845). Med. Tms (Lond.), 12, 363.

Hauser, G. A., et al. (1961). Gynaecologia (Basel); 152, 270.

Medical Women's Federation (1933). Lancet, 1, 106.

Norris, C. C. (1919). Amer. f. Obstet., 79, 767.

Rigden, W. (1870). Trans. obstet. Soc. Lond., 11, 243.

Sanes, K. I. (1918). Trans. Sect. Obstet. Gynec. Abd. Surg. Amer. med.

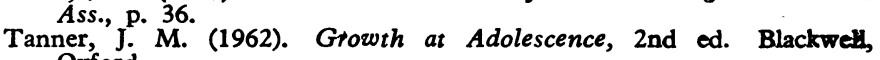
Oxford. Tilt, E. J. (1853). A Change of Life in Health and Disease. Churchin,

Way, S. (1954). 7. Obstet. Gynaec. Brit. Emp., 61, 46.
Wilson, D. C., and Sutherland, I. (1960). Ibid., 67, 320.

\title{
Urinary Gonadotrophins in Post-menopausal Women with Breast Cancer
}

\author{
F. I. R. MARTIN,* M.D., M.R.A.C.P.
}

Brit. med F., 1964, 2, 351-353

The widespread use of hormones and ablative endocrine procedures as palliative measures in metastatic breast cancer has stimulated investigation into possible hormonal abnormalities in this condition. There have been several reports of the excretion of pituitary gonadotrophins in women with metastatic carcinoma of the breast (Segaloff et al., 1951, 1954 ; Loraine et al., 1957 ; Boyland et al., 1958 ; Loraine, 1960), but there is no unanimity regarding their relation to progress or prognosis. The present investigation was undertaken to re-evaluate the prognostic value of the excretion of pituitary gonadotrophins in breast cancer. Studies were made of women with recognized metastases and women with no evidence of recurrence following treatment of the primary tumour.

\section{Methods}

Sixty women attending the follow-up clinic of the Royal Melbourne Hospital were studied. They were selected at random except for the conditions that they were co-operative, were not taking oestrogens, and were either at least three years post-menopausal or had had ovarian ablation performed more than four months previously. Most of the women studied were out-patients, and urine was collected at home and returned

\footnotetext{
* University of Melbourne Department of Medicine, Royal Melbourne Hospital.
}

to the laboratory on the day that the collection ended. Others were studied while in the hospital wards. In 52 women at least two separate 24-hour collections were obtained over a 12 -months period. In the rest only one could be obtained because of death, ill-health, or failure to co-operate.

The urine was collected without preservative, and was refrigerated until extracted by the method of Johnsen (1958). The dried extracts, dissolved in borate buffer, were assayed for total gonadotrophins by the mouse-uterus response at doubling dilutions up to 1 in 100. Results have been expressed as mouse units-1 mouse unit is equal to the reciprocal of the dilution giving a minimal positive response which in this laboratory is equivalent to $0.9 \mathrm{mg}$. H.M.G. 24 or to $0.045 \mathrm{mg}$. N.I.H.H.P.G. Details of the extraction and assay procedures and the variation in the standard responses are described elsewhere (Martin, 1964a, 1964b, 1964c). At the time of assay the details of the patients' clinical state were not known, and on completion of the investigation the case notes of each woman were independently reviewed without knowledge of the gonadotrophin excretion. Age and the duration of the disease from initial diagnosis to the date of the first assay were noted, and on the basis of the clinical records the patients were divided into two groups consisting of those with and those without clinical evidence of distant metastases or local recurrence. The women with known metastases were further classified according to their detailed records as being in "poor" or in "fair" 